\title{
Analysis of martial arts athletes' goniometric indicators
}

\author{
Podrigalo L.V. ${ }^{1}$, Volodchenko A.A. ${ }^{1}$, Rovnaya O.A. ${ }^{1}$, Stankiewicz B. ${ }^{2}$ \\ ${ }^{1}$ Kharkov State Academy of Physical Culture, Ukraine \\ ${ }^{2}$ Kazimierz Wielki University in Bydgoszcz, Poland
}

\begin{abstract}
Purpose:

comparative analysis of limbs' joints goniometric indicators of martial arts athletes; study of sportsmanship leve influence on kick boxers' movements' amplitude.

Material: $\quad$ martial arts athletes - students and senior pupils $(n=29)$ participated in the research. The participants were divided into two groups. $1^{\text {st }}$ group consisted of 18 kick boxers of age $17.44 \pm 0.34$ years. $2^{\text {nd }}$ group included 11 wrestlers of age $18.45 \pm 0.39$ years. The first group was divided into two sub-groups: sub group $1 \mathrm{a}-9$ athletes of age $18.22 \pm 0.52$ years and sportsmanship level: candidates and masters of sports. Sub group $1 \mathrm{~b}$ consisted of 9 athletes, age $(16.67 \pm 0.24)$ years and sportsmanship level from beginners to $1^{\text {st }}$ sport category. We registered movements' amplitude in wrist, shoulder, elbow, hip, knee and ankle joints.

Results: $\quad$ we confirmed the distinctions of goniometric indicators of martial arts athletes' limbs joints. It was found that sportsmanship level of kick-boxers influences to certain extent on movements' amplitude. The found distinctions reflect clearly specific of kind of sports. Wrestlers have higher amplitude of movements in wrist joints that determines reliable grip in a fight. Kick boxers have better amplitude of movements in elbow and shoulder joints. It permits to punch with higher strength. The closeness of goniometric indicators of different sportsmanship kick-boxers proves equal orientation of their training. Need in constant keeping combat stance conditions reduction of in-movement amplitude in right wrist joint and outside movement in left shoulder joint of experienced athletes.

Conclusions: increase of abduction in hip joint and reduction of bending in left knee joint illustrate specificities of punching/ kicking, optimization of their technique in experienced athletes. The higher is training experience, the more working asymmetry of joints' movements is.

Keywords: martial arts, goniometric, indicators, successfulness, asymmetry.
\end{abstract}

\section{Introduction}

Intensive physical trainings facilitate harmony of physical condition and optimization of athletes' functional state [3]. Rising of athletes' efficiency is ensured by study of special aspects of special qualities' formation and their level's optimization. In the complex of successfulness factors important place is taken by condition of muscular skeletal apparatus. Its condition can be assessed with the help of special method - goniometry.

In review of Atwater Anne E. [2] there is a conclusion about goniometric studies' prospects in sports and physical culture. Results of goniometry increase effectiveness of researches, devoted to kinesiology and bio-mechanics. Lees Adrian [20] analyses possibilities of bio-mechanical and goniometry methods' application in study movements' technique. Achievement of resuts is possible only with complex application of qualitative, quantitative and prognostic methods.

Application of goniometry in analysis of exercises with weights has been proved [6]. Goniometric researches of knee joint permit to assess the complex of movements' kinematic. In its turn, it permits to optimize mastering of this technique by athletes. Ribeiro A. \& Pascoal A. [32] analyzed active and passive movements of athletes and people, who do not practice sports, shoulder joints. Application of goniometry permitted to find high amplitude of outside rotation in discus throwers. Norris Beth S. \& Olson Sharon L. [24] confirmed the validity of goniometry and researches with the help of 2D video analysis for studying of hip and knee joints' movements. Rogers Kate \& Gibson Ann L. [33] used goniometry as the method for assessment of Pilates trainings. They proved significant flexibility improvement resulted from

\footnotetext{
(C) Podrigalo L.V., Volodchenko A.A., Rovnaya O.A.,

Stankiewicz B., 2017

doi:10.15561/20755279.2017.0406
}

8 weeks' training program.

Goniometric analysis of ballet movements was fulfilled by Quanbeck Amy E. et al. [31]. They found higher angle value of rotation in comparison with available results.

Goniometry is used rather widely in sport games. Morozova E.V. [23] used goniometry for study muscular skeletal apparatus's functional state of football players. Low flexibility, by results of goniometry, witnesses about non-elasticity of shortening of muscles and ligaments. It is one of signs of muscular skeletal apparatus's chronic over-tension.

Udochkina L.A. et al. [38] used goniometry for assessment of first maturity men - football players and those, who do not practice sports, anthropometric characteristics. They found that angle of active bending in knee joint of football players is less than in their peers. Fajzulin D.E. \& Orlov A.V. [11] proved importance of elite goal keepers in mini-football special flexibility with the help of goniometry.

Mel'nichuk K.N. [21] used goniometry for assessment of functional state of juior tennis players' muscularligament apparatus (upper limbs). High informative value of this method for mobility in elbow joint determination was confirmed. Panasiuk T.V. \& Raspopova E.A. [25] studied functional aspects of muscular-skeletal apparatus, formed under influence of dividng. They found hypertrophy of the most loaded muscular groups, high mobility in joints and changes of posture. It is caused by specificities of divers' muscular activity. воду.

Zebzeev V.V. [41] offered goniometric research as a tool of control over biathlon skiers' functional fitness. Similar resultes were obtained by Pozhidaev S.N. [29]. The author substantiated application of goniometry for testing in gymnastic. Jonsson Per et al. [17] found that different speed of thumb's movements can be a risk factor of traumatizing. Usage of electronic goniometer for study 
of fingers' movements permitted to substantially reduce errors, comparing with mechanical device.

Podrigalo L.V. et al. [26] analyzed results of goniometry of arm wrestlers' and amateurs' arm joints. They proved high movements' amplitude in athletes, especially in wrist joints. The data were interpreted as proof of hand's importance for efficiency in arm wrestling.

In other works the laws of bio-kinematic links of martial arts athletes were found:

- Maximal speed (result and value in every plane) of lower limbs' segments (thigh, shin and foot) was found as well as time of reaching this speed in fulfillment of kicks in Thae-quan do. The measurements for kinematic analysis were fulfilled with the help of two three dimensional power plates and eight chambers' motion system [9].

- Initial position of athlete as factor, influencing on Thae-quan-do technique, was determined. For measuring angle shifting of pelvis and thigh the motion system [10];

- Positions of boxers' torso and legs, which influence on successfulness of punching, were found. For obtaining kinematic data motion system Vicon 3D was used [12];

- Parameters, which, to large extent, conditioned maximal speed of foot movement in kicking, were determined. 3D kinematic of kicks of 22 Thae-quan do athletes was recorded with the help of motion system (Vicon Motion Systems Limited, Oxford, Great Britain) [30];

- For different kinds of analysis bio-mechanical parameters, connected with range of movements, strength of punch/kick and time of punch/kick, were used. 3D technology of motion system was used [39];

- Quantitative indicators of karatekas' movements, characterizing balance in competitions, were measured. Step width and angle articulation of athlete's body bio-links were registered [40];

The following are important aspects in perfection of martial arts athletes' training:

- Theoretical-methodic substantiation of sport wrestling means' usage in physical training of cadets of lyceum with advanced military-physical training [4];

- Special aspects of special workability of elite wrestlers [37].

- Optimization of physical load in Judo wrestlers' training $[1,13]$;

- Formation of Judo-wrestlers' active attitude to sports [5];

- Increase of different kinds of Judo wrestlers' muscular strength for formation of technical skills [8];

- Differentiation of body composition in athletes' training for Thae-quan do competitions [16];

- Finding of criteria of athletes' talent in combat kinds of sports and self-defense [18];

- Finding of individual aptitude of elite wrestlers to work in different regimes [36].

Analysis of researches points at possibilities to use goniometry indicators for perfection of martial arts athletes' trainings. With such approach it is recommended to combine goniometry indicators with other characteristics of athletes' actions.

The purpose of the research is comparative analysis of limbs' joints goniometric indicators of martial arts athletes; study of sportsmanship level influence on kick boxers' movements' amplitude.

\section{Material and methods}

Participants: martial arts athletes - students and senior pupils $(n=29)$ participated in the research. The participants were divided into two groups. $1^{\text {st }}$ group consisted of 18 kick boxers of age $17.44 \pm 0.34$ years. $2^{\text {nd }}$ group included 11 wrestlers of age $18.45 \pm 0.39$ years. The first group was divided into two sub-groups: sub group $1 \mathrm{a}-9$ athletes of age $18.22 \pm 0.52$ years and sportsmanship level: candidates and masters of sports. Sub group $1 b$ consisted of 9 athletes, age (16.67 \pm 0.24$)$ years and sportsmanship level from beginners to $1^{\text {st }}$ sport category.

Organization of the research: with the help of goniometer, produced by firm IGaging ${ }^{\circledR}$ we registered movements' amplitude in wrist, shoulder, elbow, hip, knee and ankle joints. We fulfilled 2-3 registrations of one and the same movement, fixing maximal indicators. In wrist, shoulder and hip joints we assessed: bending (flexio), unbending (extensio), abduction (abductio), adduction (adductio). In elbow, knee and ankle joints we assessed bending and unbending.

Statistical analysis was fulfilled with the help of licensed electronic tables Excel. We determined indicators of descriptive statistics: mean arithmetic, standard deviation and error of mean arithmetic. Confidence of differences in groups was assessed with the help of parametric Student's t-test and non-parametric tests of Wilcoxon - Manna - Whitney (U) and Wald -Wolfowits (r).

\section{Results}

The received data are presented in tables 1-3.

We found that movements' amplitude in wrist joints was higher in wrestlers. It is confirmed with Student's test for abduction of both hands. Wilcoxon - Manna-Whitney test proved substantial differences between bending of right hand $(U=29, p<0.05)$ and left hand $(U=31, p<0.05)$, unbending of right joint $(\mathrm{U}=33, \mathrm{p}<0.05)$, abduction of right $(U=29, p<0.05)$ and left joints $(U=32, p<0.05)$.

Bending amplitude in elbow joints also had significant differences. In right elbow joints the values were higher in kick boxers. It was proved by Student's t-test $(\mathrm{t}=2.33)$ and Wilcoxon - Manna - Whitney test $(U=15, \mathrm{p}<0.05)$.

Movement amplitudes in shoulder joints were higher in kick boxers. For right shoulder joint, by all kinds of movements we confirmed significant difference by three movements (with Student's t- test). For left shoulder joint we confirmed significant difference by three movements (except unbending) (with Student's t- test). Usage of non-parametric tests confirmed the made conclusions. By three kinds of movements we confirmed significant 
exceeding of amplitude in boxers. For right shoulder joint we confirmed significant difference by bending $(\mathrm{r}=2, \mathrm{p}<0.05)$, отведению $(\mathrm{U}=2, \mathrm{p}<0.05)$ and adduction $(\mathrm{U}=32, \mathrm{p}<0.05)$. For left shoulder joint the picture is (by the same three movements) (accordingly: $r=4, p<0.05$; $\mathrm{U}=30, \mathrm{p}<0.05$ and $\mathrm{U}=25, \mathrm{p}<0.05)$.

Analysis of joint movements' asymmetry also proved the presence of certain distinctions. In boxers we found noticeably higher abduction of left wrist joint, bending and abduction of right shoulder joint (by Student's test). Wrestlers, by the same criterion) had higher amplitude of left shoulder joint bending.

Results (see table 2) witness about closeness of results of different sportsmanship kick boxers. It is confirmed by the presence of differences between groups (by Student's test). At the same time usage of non parametrical criteria confirmed the presence of certain differences.

The adduction amplitude in right wrist joint of experienced athletes was less by Wald - Wolfowits criterion $(\mathrm{r}=3, \mathrm{p}<0.05)$. In the same group abduction amplitude in left shoulder joint was noticeably less as per criterion of Wilcoxon-Manna-Whitney $(U=19, \mathrm{p}<0.05)$.

Table 1. Movements' amplitudes in arms' joints of martial arts wrestlers

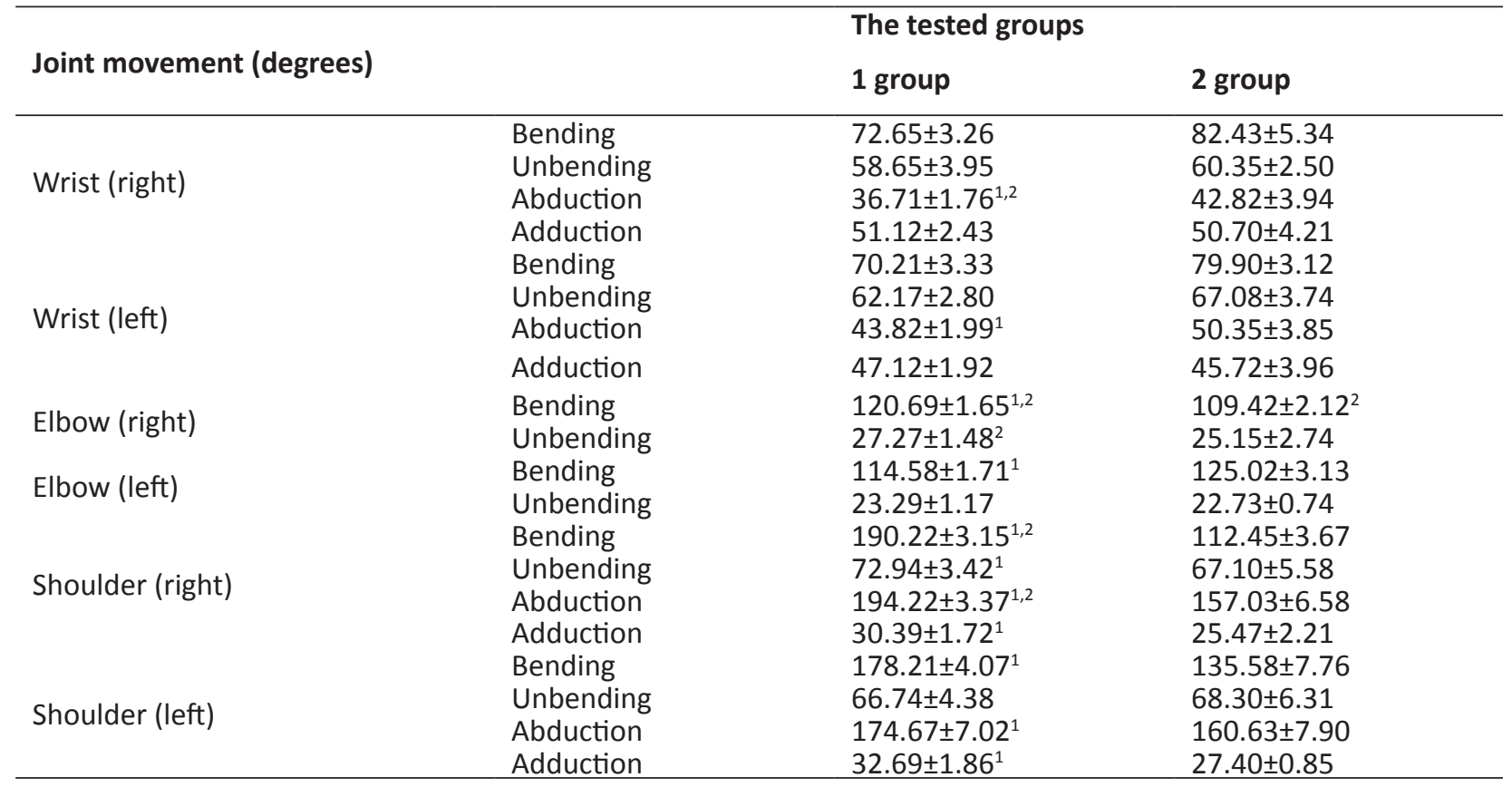

Notes: 1 - difference from wrestlers is confident ( $p<0.05)$. 2 - Difference from left arm is confident $(p<0.05)$.

Table 2. Movements' amplitudes in arms' joints of kick boxers

\begin{tabular}{|c|c|c|c|}
\hline \multirow{2}{*}{\multicolumn{2}{|c|}{ Joint movement (degrees) }} & \multicolumn{2}{|c|}{ The tested groups } \\
\hline & & 1a group & 2b group \\
\hline \multirow{4}{*}{ Wrist (right) } & Bending & $72.56 \pm 5.96$ & $72.76 \pm 2.42$ \\
\hline & Unbending & $60.93 \pm 3.88$ & $56.09 \pm 7.40$ \\
\hline & Abduction & $38.49 \pm 2.29$ & $34.70 \pm 2.69$ \\
\hline & Adduction & $49.89 \pm 4.46$ & $52.50 \pm 1.62$ \\
\hline \multirow{4}{*}{ Wrist (left) } & Bending & $71.49 \pm 5.41$ & $68.76 \pm 3.96$ \\
\hline & Unbending & $58.92 \pm 4.47$ & $65.83 \pm 2.96$ \\
\hline & Abduction & $44.60 \pm 3.14$ & $42.94 \pm 2.54$ \\
\hline & Adduction & $47.01 \pm 3.01$ & $47.24 \pm 2.49$ \\
\hline \multirow{2}{*}{ Elbow (right) } & Bending & $119.58 \pm 1.87^{1}$ & $121.95 \pm 2.87$ \\
\hline & Unbending & $28.50 \pm 1.63^{1}$ & $25.89 \pm 2.59$ \\
\hline \multirow{2}{*}{ Elbow (left) } & Bending & $112.72 \pm 2.17$ & $116.66 \pm 2.63$ \\
\hline & Unbending & $23.19 \pm 1.40$ & $23.40 \pm 2.02$ \\
\hline \multirow{4}{*}{ Shoulder (right) } & Bending & $191.80 \pm 4.43$ & $188.44 \pm 4.69$ \\
\hline & Unbending & $70.16 \pm 4.60$ & $76.08 \pm 5.18$ \\
\hline & Abduction & $190.66 \pm 3.90^{1}$ & $198.23 \pm 5.60$ \\
\hline & Adduction & $29.64 \pm 1.77$ & $31.23 \pm 3.18$ \\
\hline \multirow{4}{*}{ Shoulder (left) } & Bending & $178.10 \pm 6.19$ & $178.34 \pm 5.57$ \\
\hline & Unbending & $67.16 \pm 5.28$ & $66.26 \pm 7.56$ \\
\hline & Abduction & $164.50 \pm 11.53$ & $186.11 \pm 5.79$ \\
\hline & Adduction & $31.63 \pm 1.80$ & $33.89 \pm 3.50$ \\
\hline
\end{tabular}

Note: difference from left hand is confident $(p<0.05)$. 
Usage of Student's test permitted to confirm asymmetry of flexibility's development. More experienced athletes have higher amplitude of movement in right elbow joint by bending and unbending. The similar dependence was found for abduction in shoulder joint. In younger athletes we did not find movements' asymmetry in joints.

Analysis of movements in legs' joints confirmed made earlier assumptions about closeness of kick boxers' flexibility indicators. We found significant increase of abduction in right hip joint in 1a sub group (by criterion of Wald - Wolfowits: $r=4, p<0.05$ ). Bending in left knee joint was noticeably higher in $1 \mathrm{~b}$ sub group (by Wilcoxon-Manna-Whitney criterion: $\mathrm{U}=14, \mathrm{p}<0.05$ ). In this case Student's t-test permitted to find only tendency to confident increase $(\mathrm{p}<0.1)$.

Higher asymmetry in 1a sub group was determined. We confirmed higher adduction amplitude in left hip joint and higher bending amplitude in right ankle joint (by Student's t-test). In young athletes we found no significant differences.

\section{Discussion}

Efficiency of athletes' condition analysis directly depends on informative value of the used methodic and tests. The main criterion for their selection is consideration of kind of sports' specificity. Mirzaei B. et al. [22] determined that perfection of physical training and functional state in martial arts facilitates successfulness in fight. The authors confirmed that in junior wrestlers these factors influence on trainability.

Jafari R.A. et al. [15] studied interconnections between the following: motor activity and somatic type; anthropometric profile, body composition and physiological/physical profile of junior wrestlers. Consideration of wrestlers' profile permits to raise their competition successfulness.
Successfulness in martial arts is in direct proportion to victory in duels. It is determined by complex of factors, which includes athlete's physical and technical fitness. Athlete's technical fitness to large extent depends on movements' amplitude of limbs' joints.

Rukosuev D.A. [34] offered include complex of tests for special flexibility in U-shu athletes (10-12 yrs age) in goniometric study. On the base of the received results the author found joints, whose mobilityis always insufficient and requires additional training.

Kim T.K. \& Podlesnykh A.A. [19] used goniometric researches in analysis of Judo wrestlers' motor profile. He proved effectiveness of the methodic for rising athletes' competitiveness.

Comparison of wrestlers and impact martial arts athletes permits to consider the specificity of these kinds of sport. The similar conclusions were made by Podrigalo L.V. \& Volodchenko O.A. [28] when they used bio-mechanical approaches in martial arts. Results of wrestlers and other martial arts athletes illustrate the presence of certain distinctions, depending on different techniques in wrestling and impact martial arts. The found closeness of impact martial arts' results reflects specific aspects of these kinds of sports.

The presence of certain distinctions in wrestlers' and impact martial arts athletes' body constitution has been proved [14]. Increase of wrestlers' shoulder and forearm's circumferences as well as strength of grip in dynamic and static regimes reflects specificity of wrestling and importance of reliable grip for success.

The found differences between goniometric indicators of wrestlers and kick boxers clearly reflect specificity of kinds of sports. In wrestlers just grip takes important place in duel, as the base of effective technique's fulfillment. Reliable grip is determined by strength of hand and movement's amplitude in wrist joint. That is

Table 3. Movements' amplitudes in legs' joints of kick boxers

\begin{tabular}{llll}
\hline Joint movement (degrees) & & $\begin{array}{l}\text { The tested groups } \\
\text { 1a group }\end{array}$ & 2b group \\
\hline & Bending & $33.89 \pm 9.47$ & $102.64 \pm 5.31$ \\
Hip joint (right) & Unbending & $75.06 \pm 8.45$ & $71.48 \pm 5.04$ \\
& Abduction & $97.69 \pm 7.16$ & $86.50 \pm 6.25$ \\
& Adduction & $40.42 \pm 2.29^{1}$ & $48.14 \pm 6.15$ \\
& Bending & $99.01 \pm 8.33$ & $90.16 \pm 5.52$ \\
Hip joint (left) & Unbending & $83.54 \pm 5.41$ & $80.48 \pm 4.98$ \\
& Abduction & $86.50 \pm 10.30$ & $71.03 \pm 5.58$ \\
Knee joint (right) & Adduction & $51.03 \pm 4.13$ & $56.36 \pm 5.69$ \\
& Bending & $79.20 \pm 6.26$ & $85.63 \pm 1.54$ \\
Knee joint (left) & Unbending & $49.11 \pm 4.67$ & $44.81 \pm 3.41$ \\
& Bending & $77.17 \pm 5.26$ & $87.81 \pm 1.31^{2}$ \\
Ankle joint (right) & Unbending & $50.74 \pm 3.76$ & $47.93 \pm 1.83$ \\
& Bending & $30.26 \pm 2.05^{1}$ & $28.81 \pm 1.94$ \\
Ankle joint (left) & Unbending & $43.38 \pm 2.91$ & $48.96 \pm 3.63$ \\
& Bending & $23.83 \pm 2.30$ & $21.78 \pm 3.52$ \\
\hline
\end{tabular}

Notes: 1 - difference from left leg is confident $(p<0.05) .2$ - Tendency to confidence of differences between groups $(p<0.1)$. 
why movement's amplitude in wrist joint is noticeably higher in wrestlers.

Podrigalo L.V. et al. [26] confirmed importance of goniometric indicators in respect to wrist joint for successfulness in arm-wrestling.

For victory, in kick boxing min importance has kicking/punching that pre-conditioned the distinctions of goniometric indicators. Just it pre-determined increase of amplitude of right elbow joint's bending and practically all movements in shoulder joints of kick boxers. Just they are determining in effective punching. Higher amplitude of wrestlers' left joint's bending reflects available in them asymmetry of development. May be it is conditioned by technical peculiarities of wrestling.

The determined asymmetry of kick boxers reflects specificity of duel. In stance left hand is in frontal position. Increase of wrist joint's amplitude permits to expand the defended area. Increase of right shoulder joint's abduction amplitude permits to punch with greater strength.

Analysis of different sportsmanship kick boxers' goniometric indicators confirms similar orientation of their training. It is witnessed by closeness of the received results and absence of significant differences by most of indicators.

At the same time, the found distinctions illustrate specificity of kick boxing training. Reduction of adduction amplitude in right wrist joint and abduction in left shoulder joint in experienced athletes reflects need in sustaining of combat stance, which requires certain fixing of arms' position. This causes joints' mobility.

Increase of training experience results in joint movements' asymmetry. It is absent in young athletes. In kick boxing right arm's punches are very strong. It conditions higher bending/unbending amplitude in elbow joint and abduction in shoulder joint.

Chernicyna N.V. \& Sozailov U.A. [7] studied joints' mobility of sambo and Judo wrestlers' lower limbs joints. They found tendency to increasing mobility in hip joint of sambo and Judo wrestlers. But they did not found confident differences between these kinds of sports' indicators.

Saenko V.G. [35] used parameters of flexibility training for analyzing karate kicking. Interconnection between results of knee kick and ann flexibility indicators was found.
Analysis of movements' amplitude in legs' joints confirms made earlier conclusions about influence of specificity of kind of sport on goniometric indicators. Increase of hip joint's abduction and reduction of left knee joint's bending illustrate specific features of kicking and their technique's optimizing in experienced athletes. The similar dependence is confirmed by rising of goniometric indicators' asymmetry in athletes of 1a sub group.

\section{Conclusions}

The fulfilled researches confirmed the following: distinctions in goniometric indicators of martial arts athletes' limbs' joints; certain influence of sportsmanship on kick boxers' movements' amplitude. The found differences between indicators of wrestlers and kick boxers clearly reflect specificity of kind of sports. For wrestlers reliable grip is very important. To large extent it depends on amplitude of wrist joint's movements. These indicators were higher in $2^{\text {nd }}$ group athletes. In impact martial arts success is determined by quality and strength of punching/kicking. It pre-conditioned increase of right elbow joint's bending amplitude and movements in shoulder joints of kick boxers. The found kick boxers' asymmetry reflects specificity of duel.

The closeness of different sportsmanship kick boxers' goniometric indicators confirms equal orientation of their training. The found differences illustrate specificity of training in this kind of sports. Need in combat stance constant sustaining conditions reduction of adduction amplitude in right wrist joint and abduction in left shoulder joint of experienced athletes. Increase of right hip joint's abduction and reduction of bending in left knee joint illustrate the following: specificities of punching/kicking, optimizing of their technique in experienced athletes. Increase of training experience results in growth of working asymmetry of movements in joints. Goniometry is a simple, informative and objective tool for control and monitoring of martial arts athletes' functional state. It can be recommended for monitoring of athletes state.

\section{Conflict of interests}

The authors declare that there is no conflict of interests. 


\section{References}

1. Arziutov G, Iermakov S, Bartik P, Nosko M, Cynarski WJ. The use of didactic laws in the teaching of the physical elements involved in judo techniques. Ido Movement for Culture, 2016;16(4):21-30. doi:10.14589/ido.16.4.4

2. Atwater Anne E. Kinesiology/Biomechanics: Perspectives and Trends. Research Quarterly for Exercise and Sport. 1980;51(1):193-218. doi:10.1080/02701367.1980.10609283

3. Balbasi F, Shabani R, Nazari M. Effect of high-intensity interval training on body composition and bioenergetic indices in boys - futsal players. Physical Education of Students. 2016;20(5):42-8. doi:10.15561/20755279.2016.0506

4. Balushka LM. Perfection of physical fitness of lyceum with advanced military physical training pupils by means of sports wrestling. Pedagogics psychology medical-biological problems of physical training and sports. 2016;20(5):4-10.

5. Bliznevsky AA, Kudryavtsev MD, Iermakov SS, Jagiello W. Formation of active-effective attitude of 12-13 years' judo athletes to sports functioning in competition period. Archives of Budo. 2016;12:101-15.

6. Brandon Raphael, Howatson Glyn, Hunter Angus. Reliability of a combined biomechanical and surface electromyographical analysis system during dynamic barbell squat exercise. Journal of Sports Sciences. 2011;29(13):13891397. doi:10.1080/02640414.2011.588956

7. Chernicyna NV, Sozailov UA. Influence of sambo and Judo trainings on mobility of lower limbs' mobility. Nauchnye issledovaniia: ot teorii $k$ praktike. 2015;5(6):75-76. (in Russian)

8. Dornowski M, Jagiello W, Wolska B. Electric activity of selected agonists and antagonists registered during the measurements of different kinds of muscle strength and technical skills of 17 to 19 years old judo athletes. Archives of Budo Science of Martial Arts and Extreme Sports. 2015;11:105-13.

9. Estevan I, Falco C, Silvernail JF, Jandacka D. Comparison of Lower Limb Segments Kinematics in a Taekwondo Kick. An Approach to the Proximal to Distal Motion. Journal of Human Kinetics. 2015;47(1):41-9.

10.Estevan I, Silvernail JF, Jandacka D, Falco C. Segment coupling and coordination variability analyses of the roundhouse kick in taekwondo relative to the initial stance position. J Sport Sci. 2016;34(18):1766-73.

11.Fajzulin DE, Orlov AV. Comparative analysis of special flexibility level of elite mini-football goal keepers in preparatory and competition periods of year training cycle. Teoriia $i$ praktika fizicheskoj kul'tury. 2015;5:13-15. (in Russian)

12.Holbling D, Preuschl E, Hassmann M, Baca A. Kinematic analysis of the double side kick in pointfighting, kickboxing. J Sport Sci. 2017;35(4):317-24.

13.Iermakov SS, Arziutov GN, Jagiello W. Quick training of students to judo techniques. Archives of Budo. 2016;12:1524.

14.Iermakov SS, Podrigalo LV, Jagiełło W. Hand-grip strength as an indicator for predicting the success in martial arts athletes. Arch Budo, 2016;12: 179-186.

15.Jafari RA, Damirchi A, Mirzaei B, Nobari H. Anthropometrical profile and bio-motor abilities of young elite wrestlers. Physical Education of Students. 2016;20(6):63-9. doi:10.15561/20755279.2016.0608

16.Jagiello W. Differentiation of the body composition in taekwondo-ITF competitors of the men's Polish national team and direct based athletes. Archives of Budo. 2015;11:329-38.

17.Jonsson Per, Johnson Peter W, Hagberg Mats. Accuracy and feasibility of using an electrogoniometer for measuring simple thumb movements. Ergonomics. 2007;50(5):647-659. doi:10.1080/00140130601164490

18.Kalina RM, Jagiello W, Chodala A. The result of "testing fights in a vertical posture" as a criterion of talent for combat sports and self-defence - secondary validation (part I: the reliability). Archives of Budo Science of Martial Arts and Extreme Sports. 2015;11:229-38.

19.Kim TK, Podlesnykh AA. Individualization of training process on the base of consideration of 11-15 yrs Judo wrestlers' motor profile as the condition of their competitiveness increase. Resursy konkurentosposobnosti sportsmenov: teoriia i praktika realizacii. 2016;1(1):95-99. (in Russian)

20.Lees Adrian. Technique analysis in sports: a critical review. Journal of Sports Sciences. 2002;20(10):813-828. doi:10.1080/026404102320675657

21.Mel'nichuk KN. Physical fitness and functional state of upper limb's muscular ligament apparatus of 14-16 yrs tennis players. Fizicheskaia kul'tura, sport - nauka $i$ praktika. 2015;2:64-69. (in Russian)

22.Mirzaei B, Rahmani-Nia F, Lotfi N, Nabati SM. Trainability of body composition, aerobic power and muscular endurance of cadet wrestlers. Pedagogics psychology medical-biological problems of physical training and sports. 2016;20(5):53-7. doi:10.15561/18189172.2016.0508

23.Morozova EV. Assessment of muscular-skeletal apparatus's functional state in 16-17 yrs football players. Pedagogiko-psikhologicheskie i mediko-biologicheskie problemy fizicheskoj kul'tury i sporta. 2014;31:121-126. doi:10.14526/00_1111_16 (in Russian)

24.Norris Beth S, Olson Sharon L. Concurrent validity and reliability of two-dimensional video analysis of hip and knee joint motion during mechanical lifting. Physiotherapy Theory and Practice. An International Journal of Physical Therapy, 2011;27(7):521-530. doi:10.3109/09593985.2010. 533745

25.Panasiuk TV, Raspopova EA. Special aspects of muscularskeletal apparatus's development indiving trainings. Uchenye zapiski SPBGMU im. akad. I.P.Pavlova. 2011;18(2):108109. (in Russian)

26.Podrigalo LV, Galashko MN, Galashko NI. Goniometric researches of armwrestling sportsmen. Physical education of students, 2013; 17(1): 45-48. doi:10.6084/ m9.figshare. 156357

27.Podrigalo LV, Iermakov SS, Alekseev AF, Rovnaya OA. Studying of interconnections of morphological functional indicators of students, who practice martial arts. Physical Education of Students. 2016;20(1):64-70. doi:10.15561/20755279.2016.0109

28.Podrigalo LV, Volodchenko OA. Comparative analysis of kick boxing and other martial arts' bio-mechaniscal aspects. Visnik Chernigivs'kogo nacional'nogo pedagogichnogo universitetu, 2016;139(1):145 - 149. (in Ukrainian)

29.Pozhidaev SN. Algorithmization of flexibility testing in gymnastic. Teoriia i praktika fizicheskoj kul'tury. 2013;6:7679. (in Russian)

30.Preuschl E, Hassmann M, Baca A. A Kinematic Analysis of the Jumping Front-Leg Axe-Kick in Taekwondo. J Sport Sci Med. 2016;15(1):92-101.

31.Quanbeck Amy E, Russell Jeffrey A, Handley Sara C, Quanbeck Deborah S. Kinematic analysis of hip and knee rotation and other contributors to ballet turnout. Journal of Sports Sciences. 2017;35(4):331-338. doi:10.1080/0264041 4.2016 .1164335 
32.Ribeiro A, Pascoal A. Assessment of shoulder external rotation range-of-motion on throwing athletes: the effects of testing end-range determination (active versus passive). An International Journal of Physical Therapy. 2015;31(5):362366. doi:10.3109/09593985.2014.1003344

33.Rogers Kate, Gibson Ann L. Eight-Week Traditional Mat Pilates Training-Program Effects on Adult Fitness Characteristics. Research Quarterly for Exercise and Sport. 2009;80(3): 569-574.

34.Rukosuev DA. Pedagogic control of flexibility training in 10-12 yrs U-shu athletes. Vestnik Chuvashskogo gosudarstvennogo pedagogicheskogo universiteta, 2015;4(88):180-186. (in Russian)

35.Saenko VG. Correlation analysis of kicking in upper area strength indicators and flexibility of elite heavy weight karatekas. Physical Education of Students 2010;3:81-83. (in Russian)

36.Sawczyn S, Jagiello W, Fetisov VI, Mishchenko VS. Dependence of work capacity recovery after strenuous training sessions upon individual predisposition of skilled wrestlers to work under different energy modes. Archives of Budo. 2015;11:197-207.

37.Sazonov VV. Peculiar aspects of qualified wrestlers' special workability and supreme nervous system functioning at special training stage of preparatory period. Pedagogics psychology medical-biological problems of physical training and sports. 2017;21(1):46-50.

38.Udochkina LA, Galushko TG, Iulushev BA. Anthropometric characteristics of boys and first maturity men, who practice football and do not practice sports. Zhurnal anatomii $i$ gistopatologii. 2017;6(1):87-91. (in Russian)

39. Wasik J, Shan GB. Kinematics of the turning kick measurements obtained in testing well-trained taekwon-do athletes. Archives of Budo. 2015;11:61-7.

40.Zago M, Mapelli A, Shirai YF, Ciprandi D, Lovecchio N, Galvani C, et al. Dynamic balance in elite karateka. Journal of Electromyography and Kinesiology. 2015;25(6):894-900.

41.Zebzeev VV. Means of control over biathlon skiers' functional fitness and its indicators. Sport science of in Russia, 2015. P. 418-423. (in Russian)

\section{Information about the authors:}

Podrigalo L.V.; http://orcid.org/0000-0002-7893-524X; I.podrigalo@mail.ru; Kharkov State Academy of Physical Culture; Klochkovskaya str. 99, Kharkov, 61022, Ukraine.

Volodchenko A.A.; http://orcid.org/0000-0002-1189-3524; volodchenko_aa@mail.ru; Kharkov State Academy of Physical Culture; Klochkovskaya str. 99, Kharkov, 61022, Ukraine.

Rovnaya O.A.; http://orcid.org/0000-0003-1519-5632; rovnayaolga@mail.ru; Kharkov State Academy of Physical Culture; Klochkovskaya str. 99, Kharkov, 61022, Ukraine.

Stankiewicz B.; http://orcid.org/0000-0001-6743-1073; blazej1975@interia.pl; Kazimierz Wielki University in Bydgoszcz; Chodkiewicza str. 30, 85-064 Bydgoszcz, Poland.

Cite this article as: Podrigalo LV, Volodchenko AA, Rovnaya OA, Stankiewicz B. Analysis of martial arts athletes' goniometric indicators. Physical education of students, 2017;21(4):182-188. doi:10.15561/20755279.2017.0406

The electronic version of this article is the complete one and can be found online at: http://www.sportedu.org.ua/index.php/PES/issue/archive

This is an Open Access article distributed under the terms of the Creative Commons Attribution License, which permits unrestricted use, distribution, and reproduction in any medium, provided the original work is properly cited (http://creativecommons.org/licenses/by/4.0/deed.en).

Received: 04.05.2017

Accepted: 15.05.2017; Published: 10.08.2017 